\title{
Migration and changing law of PHC content under the action of ocean current
}

\author{
Dongfang Yang ${ }^{1,2, *}$, Qing $\mathrm{Li}^{1}$, Haixia $\mathrm{Li}^{1}$, Dong Lin ${ }^{1}$, Qi Wang ${ }^{1}$ \\ ${ }^{1}$ Accountancy School, Xijing University, Xi'an 710123, China; \\ ${ }^{2}$ North China Sea Environmental Monitoring Center, SOA, Qingdao 266033, China;
}

\begin{abstract}
According to the survey dataset of the waters of Jiaozhou Bay in May 1993, this paper studies the migration and changing process of PHC content caused by marine oil spill in the waters of Jiaozhou Bay. In May, take the center of eastern waters, H3107, as the source of marine oil spill, where PHC content is $51.00 \mu \mathrm{g} / \mathrm{L}$. Then a series of concentric circles with different gradients are formed with $\mathrm{H} 3107$ station as the center. The PHC content decreases from the high content of $51.00 \mu \mathrm{g} / \mathrm{L}$ in the center to the surroundings along the gradient, to $4.16 \mu \mathrm{g} / \mathrm{L}$ in the waters of bay mouth, $31.60 \mu \mathrm{g} / \mathrm{L}$ in the central waters of the bay, $27.00 \mu \mathrm{g} / \mathrm{L}$ in the northern waters, and $48.40 \mu \mathrm{g} / \mathrm{L}$ in the northeast waters. According to the horizontal absolute loss rate model of material content, it can be calculated that the value of horizontal absolute loss rate of PHC content in the surface layer of the water body from the eastern center to the bay mouth in May is calculated to be 0.44 Yang Dongfang absolute number; to the central waters of the bay, 0.13 Yang Dongfang absolute number; to the northern waters of the bay, 0.33 Yang Dongfang absolute number; to the northeastern waters of the bay, 0.06 Yang Dongfang absolute number. According to the horizontal relative loss rate model of material content, it is calculated that in May, from the eastern central waters to the waters of bay mouth, the horizontal relative loss rate of PHC content in the surface layer of water body is 8.67 Yang Dongfang relative number; to the central waters of the bay, 2.72 Yang Dongfang relative number; to the northern waters of the bay, 6.47 Yang Dongfang relative number; to the northeastern waters of the bay, 1.33 Yang Dongfang relative number. Therefore, taking H3107, the central point in the eastern part of Jiaozhou Bay, as the source of marine oil spills, its PHC content decreases to the surroundings, whose horizontal absolute loss rate is within 0.06-0.44 Yang Dongfang absolute number and the horizontal relative loss rate is within 1.33-8.67 Yang Dongfang relative number. The order of the horizontal absolute (relative) loss rate of PHC content from low to high is: waters in the northeast of the bay $<$ waters in the bay center $<$ waters in the north of the bay < waters in the bay mouth. The Yang Dongfang horizontal loss rate model of material content reveals the migration and changing law of PHC content during the process of ocean current carrying PHC content: 1) In the downstream direction of the ocean current, the PHC content decreases at the slowest rate, and its loss is the smallest during the migration process. In the countercurrent direction of the ocean current, the PHC content declines the fastest, and the loss is greatest during the migration process. 2) In the downstream direction of the ocean current, as the migration distance continues to increase, the PHC content continues to decline and its loss is gradually increasing during the migration process. 3) In waters where the ocean current does not pass, the PHC content decreases slowly, and the PHC content reaches a relatively high value. During the migration process, its loss is relatively small. The PHC content reaches the waters where the ocean current does not pass, and the loss content is between the loss of the PHC content carried by the ocean current in the downstream direction and the upstream direction.
\end{abstract}

\section{Introduction}

In Jiaozhou Bay, there is an oil storage base, so there are many ships going to and from Jiaozhou Bay, which sometimes results in marine oil spills. When marine oil spills occur, petroleum (PHC) will take the source of the marine oil spill as the center, forming a high-content area of PHC, and spreading around diminishingly. In this way, the ocean current transports the PHC content to the entire bay waters [1-8]. Based on the survey data in 1993, this paper analyzes the horizontal distribution and source of
PHC in the waters of Jiaozhou Bay, studies the migration process of PHC content under the action of ocean currents, and determines the changing process of PHC content in the waters of Jiaozhou Bay, which provides scientific theoretical basis for the protection of the marine environment and the maintenance of ecological sustainable development.

\footnotetext{
${ }^{*}$ Corresponding author: *dfyang @ shou.edu.cn
} 


\section{Survey waters and methods}

2.1 The natural environment of Jiaozhou Bay. Jiaozhou Bay is located in the southern part of Shandong Peninsula. Its geographical position is between $120^{\circ} 04^{\prime}-120^{\circ} 23^{\prime} \mathrm{E}$ and $35^{\circ} 58^{\prime}-36^{\circ} 18^{\prime} \mathrm{N}$. It is bounded by the line connecting Tuan Island and Xuejia Island, and is connected to the Yellow Sea. With an area of about $446 \mathrm{~km}^{2}$ and an average water depth of about $7 \mathrm{~m}$, it is a typical semi-enclosed bay. There are more than a dozen rivers entering the sea in Jiaozhou Bay, among which the Dagu River, Yang River and the Haibo River, Licun River and Loushan River in Qingdao City with larger runoff and sand content. These rivers are all seasonal rivers, and the river hydrological characteristics have obvious seasonal changes $[9,10]$.

2.2 Materials and methods. The survey data of PHC content in Jiaozhou Bay in May, September and October 1992 used in this study are provided by the North Sea Monitoring Center of the State Oceanic Administration. Seven stations were set up in the waters of Jiaozhou Bay to take water samples: stations H3101, H3102, H3103, H3104, H3105, H3106 and H3107 (Figure 1). Sampling was conducted three times in May, September and October 1993, respectively. Water samples were taken according to the water depth (surface and bottom layers were taken when the depth $>10 \mathrm{~m}$, and only the surface layer was taken when the depth $<10 \mathrm{~m}$ ) for investigation and sampling. The survey of PHC content in Jiaozhou Bay water body was carried out according to the national standard method, which was recorded in the national "Marine Monitoring Code" (1991) [11].

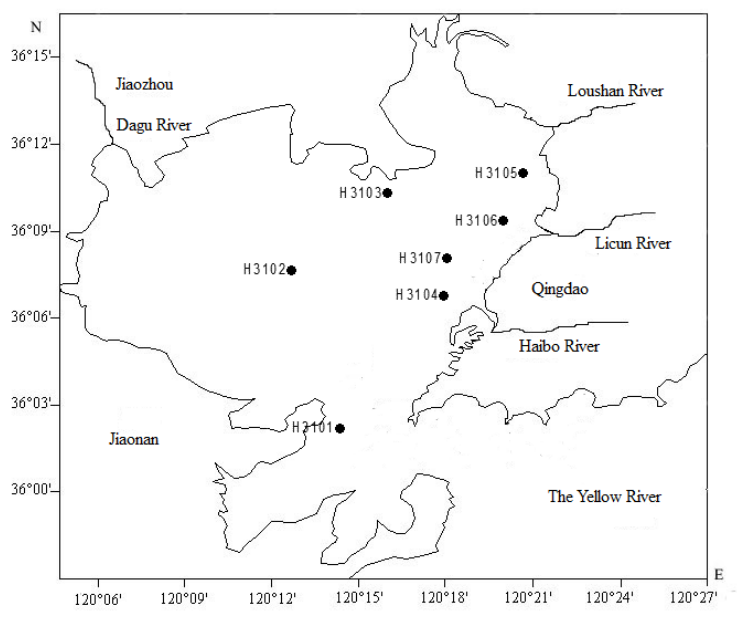

Fig.1 Investigation sites in Jiaozhou Bay

\section{Results}

3.1 Sources. In May, in the eastern part of Jiaozhou Bay, the PHC content reaches a high level of $51.00 \mu \mathrm{g} / \mathrm{L}$

Table 1. Locations and values of PHC content of five stations, H3107, H3101, H3102, H3103, and H3106

\begin{tabular}{|l|l|l|l|}
\hline Station & Longitude & Latitude & PHC content $(\mu \mathrm{g} / \mathrm{L})$ \\
\hline H3107 & $120^{\circ} 19^{\prime} 18^{\prime \prime}$ & $36^{\circ} 08^{\prime} 06^{\prime \prime}$ & 51.00 \\
\hline H3101 & $120^{\circ} 14^{\prime} 00^{\prime \prime}$ & $36^{\circ} 02^{\prime} 00^{\prime \prime}$ & 4.16 \\
\hline H3102 & $120^{\circ} 11^{\prime} 48^{\prime \prime}$ & $36^{\circ} 07^{\prime} 30^{\prime \prime}$ & 31.60 \\
\hline
\end{tabular}

at $\mathrm{H} 3107$ station in the eastern central waters, forming a high content area of PHC with $\mathrm{H} 3107$ station as the center and a series of concentric circles with different gradients. The PHC content decreases from the high content of $51.00 \mu \mathrm{g} / \mathrm{L}$ in the center to the surroundings along the gradient, to $4.16 \mu \mathrm{g} / \mathrm{L}$ in the waters of bay mouth, $31.60 \mu \mathrm{g} / \mathrm{L}$ in the central waters of the bay, $27.00 \mu \mathrm{g} / \mathrm{L}$ in the northern waters of the bay, and $48.40 \mu \mathrm{g} / \mathrm{L}$ in the northeastern waters of the bay (Figure 2).

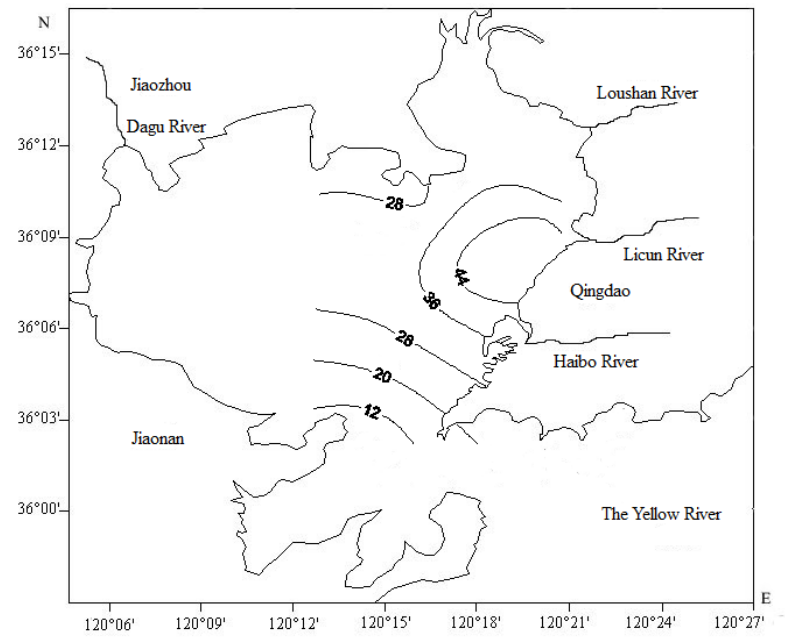

Fig.2 PHC content distribution at the surface in Jiaozhou Bay in $\operatorname{May}(\mu \mathrm{g} / \mathrm{L})$

In May, a high-content area of PHC is formed in the waters of eastern center of Jiaozhou Bay, which indicates that the source of PHC is the transportation of oil spilled at sea, and its $\mathrm{PHC}$ content is $51.00 \mu \mathrm{g} / \mathrm{L}$. The transported $\mathrm{PHC}$ content declines along the gradient, which leads to a decrease in the PHC content gradient to the surrounding area, reaching $4.16 \mu \mathrm{g} / \mathrm{L}$ in the waters of the bay mouth, $31.60 \mu \mathrm{g} / \mathrm{L}$ in the central waters of the bay, $27.00 \mu \mathrm{g} / \mathrm{L}$ in the northern waters of the bay, and $48.40 \mu \mathrm{g} / \mathrm{L}$ in the northeastern waters of the bay. Then, at the same time, whether the horizontal loss of the same PHC content during the ocean transportation along different directions is the same.

\subsection{Distance from central station to surrounding} stations. In May, in the central waters of the eastern part of Jiaozhou Bay, taking H3107 station as the center, the three surrounding stations are H3101 station in the bay mouth, H3102 station in the center of the bay, H3103 station in the north of the bay, and H3106 station in the northeast of the bay. Figure 3 shows the distances from the central station H3107 in the eastern part of Jiaozhou Bay to the station H3101 in the bay mouth, station $\mathrm{H} 3102$ in the center, station H3103 in the north, and station $\mathrm{H} 3106$ in the northeast, respectively. Choose these five stations H3107, H3101, H3102, H3103, H3106 to get the value of PHC content (Table 1). 


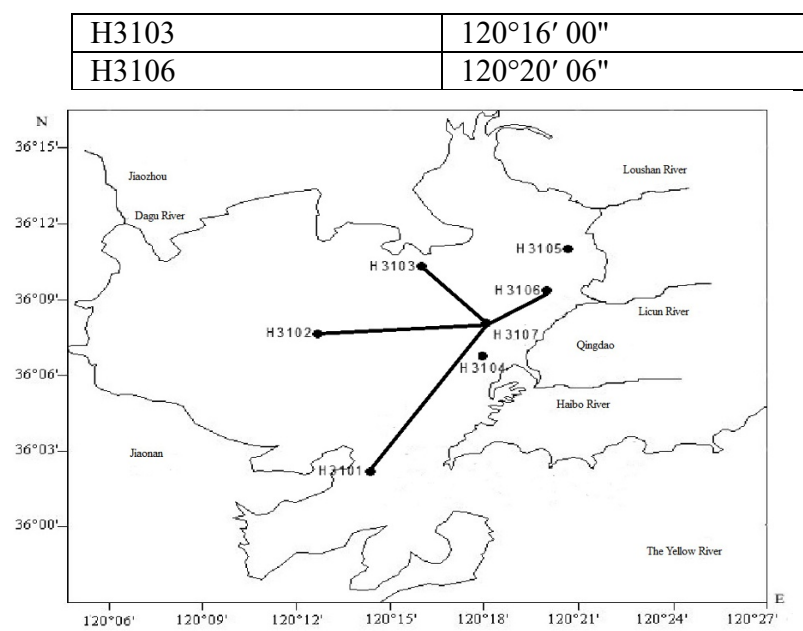

Figure 3. Connections from the central station in the eastern part of Jiaozhou Bay to other stations

Calculate the distance from station H3107 in the eastern center of Jiaozhou Bay to station H3101 in the bay mouth:

Assuming that the distance from point $\mathrm{H} 3107$ to point $\mathrm{H} 3101$ is $L_{1}$. According to $1^{\prime}=1858 \mathrm{~m}$, the distance $L_{1}$ is calculated as

$\mathrm{L}_{1}^{2}=[(19-14+18 / 60-00 / 60) \times 1858]^{2}+[(8-2+6 / 60-0 / 60)$ $\times 1858]^{2} \quad(1)$

$$
\mathrm{L}_{1}=5.70 \times 1858=10590.60(\mathrm{~m})
$$

Calculate the distance from station $\mathrm{H} 3107$ in the eastern center of Jiaozhou Bay to station H3102 in the center of the bay: Assuming that the distance from point $\mathrm{H} 3107$ to point $\mathrm{H} 3102$ is $\mathrm{L}_{2}$. According to $1^{\prime}=1858 \mathrm{~m}$, the distance $L_{2}$ is calculated as

$$
\begin{aligned}
& \mathrm{L}_{2}{ }^{2}=[(19-11+18 / 60-48 / 60) \times 1858]^{2}+[(8-7+6 / 60-30 / 60) \\
& \times 1858]^{2} \quad(3) \\
& \mathrm{L}_{2}=7.52 \times 1858=13972.16(\mathrm{~m})
\end{aligned}
$$

Calculate the distance from station $\mathrm{H} 3107$ in the eastern center of Jiaozhou Bay to station H3103 in the north of the bay: Assuming that the distance from point $\mathrm{H} 3107$ to point $\mathrm{H} 3103$ is $\mathrm{L}_{3}$. According to $1^{\prime}=1858 \mathrm{~m}$, the distance $\mathrm{L}_{3}$ is calculated as

$$
\mathrm{L}_{3}{ }^{2}=[(19-16+18 / 60-0 / 60) \times 1858]^{2}+[(8-10+6 / 60-12 / 60)
$$
$\times 1858]^{2} \quad(5)$

$$
\mathrm{L}_{3}=3.91 \times 1858=7264.78(\mathrm{~m})
$$

Calculate the distance from station H3107 in the eastern center of Jiaozhou Bay to station H3106 in the northeast of the bay: Assuming that the distance from point $\mathrm{H} 3107$ to point $\mathrm{H} 3106$ is $\mathrm{L}_{4}$. According to $1^{\prime}=1858 \mathrm{~m}$, the distance $\mathrm{L}_{4}$ is calculated as

$\mathrm{L}_{4}{ }^{2}=[(19-20+18 / 60-6 / 60) \times 1858]^{2}+[(8-10+6 / 60-0 / 60)$ $\times 1858]^{2}(7)$

$$
\mathrm{L}_{4}=2.06 \times 1858=3827.48(\mathrm{~m})
$$

\subsection{Yang Dongfang horizontal loss rate model of} material content. The author proposes the Yang Dongfang horizontal loss rate model of material content, which is composed of the horizontal absolute loss rate model of material content and the horizontal relative loss rate model of material content.

Horizontal absolute loss rate model of material content: Assuming that the surface material content in the

\begin{tabular}{|l|l|}
\hline $36^{\circ} 10^{\prime} 12^{\prime \prime}$ & 27.00 \\
\hline $36^{\circ} 10^{\prime} 00^{\prime \prime}$ & 48.40 \\
\hline
\end{tabular}

water body decreases from the value a at point $A$ to the value $\mathrm{b}$ at point $\mathrm{B}$, and the distance from point $\mathrm{A}$ to point $\mathrm{B}$ is $\mathrm{L}$, consider the horizontal absolute loss rate of material content as $\mathrm{V}_{\text {sp. }}$. Thus, the horizontal absolute loss rate model of the material content can be obtained: $\mathrm{V}_{\text {asp }}=(\mathrm{a}-\mathrm{b}) / \mathrm{L}$

Then, consider the horizontal relative loss rate of material content as $\mathrm{V}_{\mathrm{sp}}$. The horizontal relative loss rate model of material content is: $\mathrm{V}_{\text {rsp }}=[(\mathrm{a}-\mathrm{b}) / \mathrm{a}] / \mathrm{L}=(\mathrm{a}-\mathrm{b}) / \mathrm{a} \mathrm{L} \quad$ (10)

Starting from the spatial scale, this model reveals the amount of loss per unit distance during the migration of material content on the horizontal plane. The horizontal absolute loss rate of material content indicates the absolute loss per unit distance, and the horizontal relative loss rate of material content indicates the relative loss per unit distance.

3.4 Simplification of units. The units of the horizontal absolute loss rate and the horizontal relative loss rate of petroleum are more complicated and need to be simplified. The author, therefore, calls $\times 10^{-5}(\mathrm{mg} / \mathrm{L}) /$ $\mathrm{m}$ as Yang Dongfang number, which can also be written in English, ydf.

For example, the horizontal absolute loss rate of PHC content is $\mathrm{V}_{\text {asp }}=30.84 \times 10^{-5}(\mathrm{mg} / \mathrm{L}) / \mathrm{m}$, which can be called 30.84 Yang Dongfang absolute number, or 30.84 ydfa.

The horizontal relative loss rate of $\mathrm{PHC}$ content is $\mathrm{V}_{\mathrm{rsp}}=7.78 \times 10^{-5} / \mathrm{m}$, which can be called 7.78 Yang Dongfang relative number or $7.78 \mathrm{ydfr}$.

Therefore, in any water body, the unit of horizontal loss of any material content can be measured by Yang Dongfang absolute number and Yang Dongfang relative number or ydfa and ydfr.

\subsection{Horizontal loss rate from eastern center to} the bay mouth. In May, a high-content area of PHC is formed in the water body of $\mathrm{H} 3107$, the central point of the eastern part of Jiaozhou Bay, which indicates that the PHC sources from the transportation of oil spilled at sea, and the PHC content is $51.00 \mu \mathrm{g} / \mathrm{L}$. In the waters of bay mouth, the PHC content in the surface layer of the water body is $4.16 \mu \mathrm{g} / \mathrm{L}$ from point $\mathrm{H} 3107$ to point $\mathrm{H} 3101$.

Based on the Yang Dongfang horizontal loss rate model of material content, the horizontal absolute loss rate and horizontal relative loss rate of PHC content can be calculated.

In May, the content of PHC in the surface waters decreases from $51.00 \mu \mathrm{g} / \mathrm{L}$ in the station $\mathrm{H} 3107$ to $4.16 \mu \mathrm{g} / \mathrm{L}$ in the station $\mathrm{H} 3101$. The horizontal absolute loss rate of $\mathrm{PHC}$ content is $\mathrm{V}_{\text {asp }}=(51.00-4.16) /$ $10590.60=442.27 \times 10^{-5}(\mu \mathrm{g} / \mathrm{L}) / \mathrm{m}=0.44 \times 10^{-5}(\mathrm{mg} / \mathrm{L}) / \mathrm{m}$ $=0.44 \mathrm{ydfa}$. The horizontal relative loss rate of $\mathrm{PHC}$ content is $\mathrm{V}_{\mathrm{rsp}}=8.67 \times 10^{-5} / \mathrm{m}=8.67 \mathrm{ydfr}$.

Therefore, in May, the source of PHC content in the waters of Jiaozhou Bay is the transportation of marine oil spills. From station H3107 to station H3101, the 
horizontal absolute loss rate of PHC content in the surface waters is 0.44 Yang Dongfang absolute number, and the horizontal relative loss rate is 8.67 Yang Dongfang relative number.

\subsection{Horizontal loss rate from the eastern center to the center of the bay. In May, it forms a} high-content area of PHC in the eastern central waters of the bay, where is the station H3107. It indicates that the source of PHC is the transportation of marine oil spills, and the content of $\mathrm{PHC}$ is $51.00 \mu \mathrm{g} / \mathrm{L}$. In the central waters of the bay, the PHC content in the surface from the point $\mathrm{H} 3107$ to the point $\mathrm{H} 3102$ is $31.60 \mu \mathrm{g} / \mathrm{L}$.

According to the Yang Dongfang horizontal loss rate model of material content, the horizontal absolute loss rate and the horizontal relative loss rate of PHC content can be calculated out.

In May, the PHC content in the surface waters decreases from $51.00 \mu \mathrm{g} / \mathrm{L}$ at the point of $\mathrm{H} 3107$ to $31.60 \mu \mathrm{g} / \mathrm{L}$ at the point of $\mathrm{H} 3102$. The horizontal absolute loss rate of PHC content is $\mathrm{V}_{\text {asp }}=(51.00-31.60) /$ $13972.16=138.84 \times 10^{-5}(\mu \mathrm{g} / \mathrm{L}) / \mathrm{m}=0.13 \times 10^{-5}(\mathrm{mg} / \mathrm{L}) /$ $\mathrm{m}=0.13 \mathrm{ydfa}$. And the horizontal relative loss rate of $\mathrm{PHC}$ content is $\mathrm{V}_{\mathrm{rsp}}=2.72 \times 10^{-5} / \mathrm{m}=2.72 \mathrm{ydfr}$.

Therefore, in May, the source of PHC content in the waters of Jiaozhou Bay is the transportation of marine oil spills. From the point H3107 to the point H3102 in the surface central waters of the bay, the horizontal absolute loss rate of PHC content is 0.13 Yang Dongfang absolute number and the horizontal relative loss rate of $\mathrm{PHC}$ content is 2.72 Yang Dongfang relative number.

\subsection{Horizontal loss rate from the eastern center} to the north of the bay. In May, it forms a high-content area of PHC in the eastern central waters of the bay, where is the station H3107. It indicates that the source of PHC is the transportation of marine oil spills, and the content of $\mathrm{PHC}$ is $51.00 \mu \mathrm{g} / \mathrm{L}$. In the northern waters of the bay, the PHC content in the surface from the point $\mathrm{H} 3107$ to the point $\mathrm{H} 3103$ is $27.00 \mu \mathrm{g} / \mathrm{L}$.

According to the Yang Dongfang horizontal loss rate model of material content, the horizontal absolute loss rate and the horizontal relative loss rate of PHC content can be calculated out.

In May, the PHC content in the surface waters decreases from $51.00 \mu \mathrm{g} / \mathrm{L}$ at the point of $\mathrm{H} 3107$ to $27.00 \mu \mathrm{g} / \mathrm{L}$ at the point of $\mathrm{H} 3103$. The horizontal absolute loss rate of PHC content is $\mathrm{V}_{\text {asp }}=(51.00-27.00) /$ $7264.78=330.36 \times 10^{-5}(\mu \mathrm{g} \quad / \mathrm{L}) / \mathrm{m}=0.33 \times 10^{-5}(\mathrm{mg} / \mathrm{L}) /$ $\mathrm{m}=0.33 \mathrm{ydfa}$. And the horizontal relative loss rate of $\mathrm{PHC}$ content is $\mathrm{V}_{\mathrm{rsp}}=6.47 \times 10^{-5} / \mathrm{m}=6.47 \mathrm{ydfr}$.

Therefore, in May, the source of PHC content in the waters of Jiaozhou Bay is the transportation of marine oil spills. From the point H3107 to the point H3103 in the surface northern waters of the bay, the horizontal absolute loss rate of PHC content is 0.33 Yang Dongfang absolute number and the horizontal relative loss rate of PHC content is 6.47 Yang Dongfang relative number.
3.8 Horizontal loss rate from the eastern center to the northeast of the bay. In May, it forms a high-content area of PHC in the eastern central waters of the bay, where is the station H3107. It indicates that the source of PHC is the transportation of marine oil spills, and the content of $\mathrm{PHC}$ is $51.00 \mu \mathrm{g} / \mathrm{L}$. In the northeastern waters of the bay, the PHC content in the surface from the point $\mathrm{H} 3107$ to the point $\mathrm{H} 3106$ is $48.40 \mu \mathrm{g} / \mathrm{L}$.

According to the Yang Dongfang horizontal loss rate model of material content, the horizontal absolute loss rate and the horizontal relative loss rate of PHC content can be calculated out.

In May, the PHC content in the surface waters decreases from $51.00 \mu \mathrm{g} / \mathrm{L}$ at the point of $\mathrm{H} 3107$ to $48.40 \mu \mathrm{g} / \mathrm{L}$ at the point of $\mathrm{H} 3106$. The horizontal absolute loss rate of PHC content is $\mathrm{V}_{\text {asp }}=(51.00-48.40) /$ $3827.48=67.92 \times 10^{-5}(\mu \mathrm{g} \quad / \mathrm{L}) / \mathrm{m}=0.06 \times 10^{-5}(\mathrm{mg} / \mathrm{L}) /$ $\mathrm{m}=0.06 \mathrm{ydfa}$. And the horizontal relative loss rate of $\mathrm{PHC}$ content is $\mathrm{V}_{\mathrm{rsp}}=1.33 \times 10^{-5} / \mathrm{m}=1.33 \mathrm{ydfr}$.

Therefore, in May, the source of PHC content in the waters of Jiaozhou Bay is the transportation of marine oil spills. From the point H3107 to the point H3106 in the surface northeastern waters of the bay, the horizontal absolute loss rate of PHC content is 0.06 Yang Dongfang absolute number and the horizontal relative loss rate of PHC content is 1.33 Yang Dongfang relative number.

\section{Discussion}

4.1 Horizontal content changing in the same source. In May, a high-content area of PHC is formed in the eastern central waters of Jiaozhou Bay, which indicates that the source of PHC is the transportation of marine oil spills, and its PHC content is $51.00 \mu \mathrm{g} / \mathrm{L}$. A series of concentric circles with different gradients are formed with the $\mathrm{H} 3107$ station as the center. The transported PHC content declines along the gradient, which leads to a decrease in the PHC content gradient to the surrounding area, reaching $4.16 \mu \mathrm{g} / \mathrm{L}$ in the waters of the bay mouth, $31.60 \mu \mathrm{g} / \mathrm{L}$ in the central waters of the bay, $27.00 \mu \mathrm{g} / \mathrm{L}$ in the northern waters of the bay, and $48.40 \mu \mathrm{g} / \mathrm{L}$ in the northeastern waters of the bay (Figure 2).

Table 2 can be calculated out based on the horizontal absolute loss rate model of material content. In May, the horizontal absolute loss rate of PHC content in the surface waters from eastern center of the bay to the bay mouth is 0.44 Yang Dongfang absolute number. In the central waters of the bay, the horizontal absolute loss rate of PHC content in the surface layer is 0.13 Yang Dongfang absolute number. In the northern waters of the bay, the horizontal absolute loss rate of PHC content in the surface layer is 0.33 Yang Dongfang absolute number. In the northeastern waters of the bay, the horizontal absolute loss rate of PHC content in the surface is 0.06 Yang Dongfang absolute number. Therefore, taking $\mathrm{H} 3107$, the central point in the eastern part of Jiaozhou Bay, as the source of marine oil spills, its PHC content decreases to the surroundings, and the horizontal absolute loss rate of $\mathrm{PHC}$ content ranges within 
0.06-0.44 Yang Dongfang absolute number.

Some values in Table 2 can be calculated out based on the horizontal relative loss rate model of material content. In May, the horizontal relative loss rate of PHC content in the surface waters from eastern center of the bay to the bay mouth is 8.67 Yang Dongfang relative number. In the central waters of the bay, the horizontal relative loss rate of $\mathrm{PHC}$ content in the surface layer is 2.72 Yang Dongfang relative number. In the northern waters of the bay, the horizontal relative loss rate of PHC content in the surface layer is 6.47 Yang Dongfang relative number. In the northeastern waters of the bay, the horizontal relative loss rate of PHC content in the surface is 1.33 Yang Dongfang relative number. Therefore, taking $\mathrm{H} 3107$, the central point in the eastern part of Jiaozhou Bay, as the source of marine oil spills, its PHC content decreases to the surroundings, and the horizontal relative loss rate of PHC content ranges within 1.33-8.67 Yang Dongfang relative number.

Table 2 The loss rate of PHC content in the eastern central waters

\begin{tabular}{|l|l|l|l|l|}
\hline Time & May & May & May & May \\
\hline In the eastern central waters & $\begin{array}{l}\text { From H3107 to } \\
\text { H3101 }\end{array}$ & $\begin{array}{l}\text { From H3107 to } \\
\text { H3102 }\end{array}$ & $\begin{array}{l}\text { From H3107 to } \\
\text { H3103 }\end{array}$ & $\begin{array}{l}\text { From H3107 to } \\
\text { H3106 }\end{array}$ \\
\hline Variation range of PHC content & $4.16-51.00$ & $31.60-51.00$ & $27.00-51.00$ & $48.40-51.00$ \\
\hline $\begin{array}{l}\text { Horizontal absolute loss rate of } \\
\text { PHC content }\end{array}$ & 0.44 & 0.13 & 0.33 & 0.06 \\
\hline $\begin{array}{l}\text { Horizontal relative loss rate of } \\
\text { PHC content }\end{array}$ & 8.67 & 2.72 & 6.47 & 1.33 \\
\hline $\begin{array}{l}\text { Characteristics of PHC content } \\
\text { values }\end{array}$ & Same time, same source, various distance \\
\hline
\end{tabular}

\subsection{Characteristics of PHC content from the} same source. At the same time, from the same starting point to different end points, the PHC content of the starting point is the same, and the absolute loss per unit distance is different.

In May, from the eastern central waters to the waters of bay mouth, the horizontal absolute loss rate of PHC content in the surface waters is the highest at 0.44 Yang Dongfang absolute number. In the waters of bay mouth, there is no influence and interference from any source of PHC content. In this way, from the eastern central waters to the waters of bay mouth, the horizontal absolute loss rate of PHC content reaches the highest value.

In May, from the eastern central waters to the central waters of Jiaozhou Bay, the horizontal absolute loss rate of PHC content in the surface layer of the water body is the lowest at 0.13 Yang Dongfang absolute number. In the central waters of the bay, there is no input of PHC content, and there is little influence and interference on the PHC content derived from marine oil spills. In this way, from the eastern central waters to the central waters of the bay, the horizontal absolute loss rate of $\mathrm{PHC}$ content is relatively low.

In May, from the eastern central waters to the northern waters of Jiaozhou Bay, the horizontal absolute loss rate of $\mathrm{PHC}$ content in the surface layer of the water body is relatively high at 0.33 Yang Dongfang absolute number. In the northern waters of the bay, there is no input of PHC content, and there is little influence and interference on the PHC content derived from marine oil spills. In this way, from the eastern central waters to the northern waters of the bay, the horizontal absolute loss rate of $\mathrm{PHC}$ content reaches relatively high.

In May, from the eastern central waters to the northeastern waters of Jiaozhou Bay, the horizontal absolute loss rate of PHC content in the surface layer of the water body is the lowest at 0.06 Yang Dongfang absolute number. In the northeastern waters of the bay, there is no input of PHC content, and there is little influence and interference on the PHC content derived from marine oil spills. In this way, from the eastern central waters to the northeastern waters of the bay, the horizontal absolute loss rate of PHC content reaches the lowest.

According to the order of horizontal absolute loss rate of PHC content from low to high: Northeastern waters of the bay $<$ Central waters of the bay $<$ Northern waters of the bay $<$ waters in the bay mouth, the order of horizontal absolute loss rate of PHC content is the same with it of horizontal relative loss rate of $\mathrm{PHC}$ content. The order of horizontal relative loss rate of $\mathrm{PHC}$ content from low to high is: Northeastern waters of the bay $<$ Central waters of the bay $<$ Northern waters of the bay $<$ Waters in the bay mouth. This sequence is the opposite that the PHC content from the center of the high content of $51.00 \mu \mathrm{g} / \mathrm{L}$ decreases along the gradient to the surroundings. The order of PHC content from low to high is: Waters in the bay mouth $<$ Northern waters of the bay $<$ Central waters of the bay $<$ Northeastern waters of the bay.

Therefore, taking the eastern center of Jiaozhou Bay as the source of marine oil spills at $51.00 \mu \mathrm{g} / \mathrm{L}$, a series of concentric circles with different gradients are formed. Then along the gradient, the PHC content decreases to the waters of bay mouth, central waters, northern waters and northeastern waters. The order of PHC content from low to high is: bay mouth waters $<$ northern waters $<$ central waters $<$ northeastern waters. In this way, the horizontal absolute (relative) loss rate of PHC content has a descending order: northeastern waters $<$ central waters $<$ northern waters $<$ waters in the bay mouth. The PHC content shows the value from the same point of the marine oil spill to this water area, and the horizontal absolute (relative) loss rate of PHC content shows the process value from the same point of the marine oil spill to this water area. Therefore, the order of PHC content is opposite to the order of horizontal absolute (relative) loss rate of $\mathrm{PHC}$ content.

\subsection{Transportation process of ocean current.} Currents in the open waters pass from the bay mouth to inner of the bay. And the ocean currents circle the nearshore waters in the bay, reach the western waters of the bay mouth, leaving and then leave the Jiaozhou Bay 
(Figure 2).

In May, from the eastern central waters to the waters of bay mouth, it spreads against the ocean currents. Without the influence and interference of any source of PHC content in the waters of bay mouth, from the eastern central waters to the waters of bay mouth, the horizontal absolute (relative) loss rate of PHC content reaches the highest value. This shows that when spreading against the ocean currents, the PHC content decreases the fastest, and the PHC content reaches the lowest value. The PHC content loses the most during the migration process.

In May, from the eastern central waters to the northeastern waters of the bay, it spreads along the ocean currents. Without the influence and interference of any source of PHC content in the northeastern waters of bay, from the eastern central waters to the northeastern waters of bay, the horizontal absolute (relative) loss rate of PHC content reaches the lowest value. This shows that when spreading along the ocean currents, the PHC content decreases the slowest, and the PHC content reaches the highest value. The PHC content loses the least during the migration process.

In May, from the eastern central waters to the eastern waters of the bay, it spreads along the ocean currents. Without the influence and interference of any source of PHC content in the central waters of bay, from the eastern central waters to the central waters of bay, the horizontal absolute (relative) loss rate of PHC content reaches a relatively lower value. This shows that when spreading along the ocean currents, the PHC content decreases at a relative low rate, and the PHC content reaches a relative higher value. The loss of PHC content in the migration process is relatively small.

In May, from the eastern central waters to the northern waters of the bay, it spreads along the ocean currents. Without the influence and interference of any source of PHC content in the northern waters of bay, from the eastern central waters to the northern waters of bay, the horizontal absolute (relative) loss rate of PHC content reaches a relatively higher value. This shows that when spreading along the ocean currents and as the moving distance of ocean currents becomes longer, the PHC content decreases faster, and the PHC content reaches a relatively low value. The loss of PHC content during the migration process is relatively large.

The PHC content carried by the offshore ocean currents shows the changing law of the PHC content during different migration processes(Figure 4). 1) Along the downstream and upstream directions of ocean currents, the PHC content carried by the ocean currents in the open waters shows different changing results. In the downstream direction of ocean currents, the decline rate of PHC content reaches the slowest, and the loss of $\mathrm{PHC}$ content is the smallest during the migration process. In the countercurrent direction of ocean currents, the PHC content decreases the fastest, and the PHC content loses the most during the migration process. 2) Along the downstream direction of the ocean currents, the length of the migration distance of the PHC content carried by the ocean current in the open waters shows different changing results. In the downstream direction of the ocean current, as the migration distance of the PHC content continues to increase, the PHC content is continuously decreasing, and the loss of the PHC content is gradually increasing during the migration process. 3) In waters where ocean currents do not pass, the PHC content carried by ocean currents in the open waters shows different results. In waters where ocean currents do not pass, the PHC content decreases slowly, and the PHC content reaches a relatively high value. The loss of the PHC content during the migration process is relatively small. The loss of PHC content is between the loss of the PHC content carried by the ocean current in the downstream direction and the upstream direction.

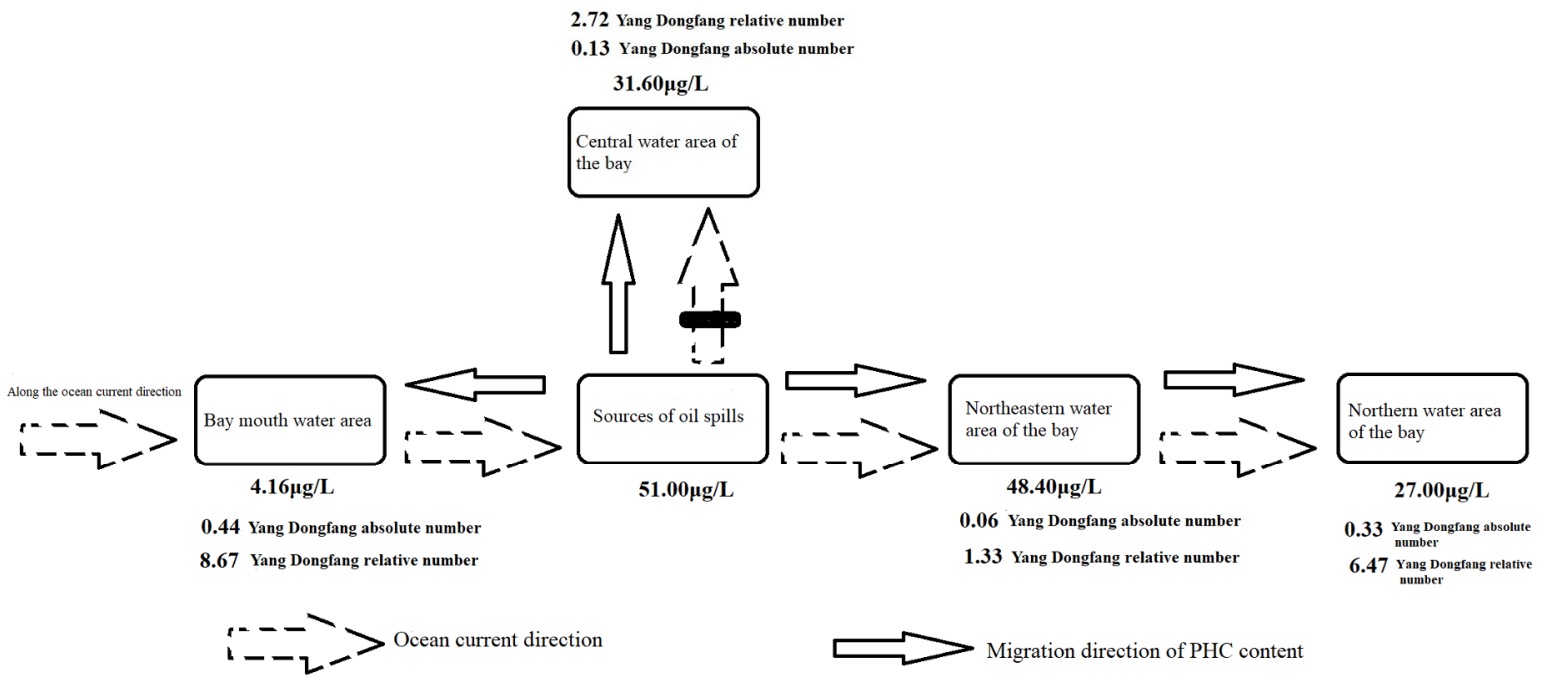

Figure 4. Changing law in the migration process of PHC content

Therefore, according to the Yang Dongfang horizontal loss rate model of material content, it is possible to calculate and quantify the migration and changing process of PHC content decreasing along the gradient to the surroundings.

\section{Conclusion}

In May, taking the eastern central point of Jiaozhou Bay, $\mathrm{H} 3107$, as the source of marine oil spills, the PHC content is $51.00 \mu \mathrm{g} / \mathrm{L}$. A series of concentric circles with 
different gradients are formed with the H3107 station as the center. The PHC content decreases from the high content of $51.00 \mu \mathrm{g} / \mathrm{L}$ in the center to the surroundings along the gradient, to $4.16 \mu \mathrm{g} / \mathrm{L}$ in the waters of bay mouth, $31.60 \mu \mathrm{g} / \mathrm{L}$ in the central waters of the bay, $27.00 \mu \mathrm{g} / \mathrm{L}$ in the northern waters of the bay, and $48.40 \mu \mathrm{g} / \mathrm{L}$ in the northeastern waters of the bay.

According to the horizontal absolute loss rate model of material content, it can be calculated that the horizontal absolute loss rate of PHC content in the surface waters from eastern central part to the area of bay mouth is 0.44 Yang Dongfang absolute number in May (Table 2). In the central waters of the bay, the horizontal absolute loss rate of PHC content in the surface waters is 0.13 Yang Dongfang absolute number. The horizontal absolute loss rate of PHC content in the surface layer of the northern waters is 0.33 Yang Dongfang absolute number. To the northeastern waters of the bay, the horizontal absolute loss rate of PHC content in the surface waters is 0.06 Yang Dongfang absolute number. Therefore, taking H3107, the central point in the eastern part of Jiaozhou Bay, as the source of marine oil spills, its PHC content decreases to the surroundings, and the horizontal absolute loss rate of PHC content is within 0.06-0.44 Yang Dongfang absolute number.

According to the horizontal relative loss rate model of material content, it can be calculated that the horizontal relative loss rate of $\mathrm{PHC}$ content in the surface waters from eastern central part to the area of bay mouth is 8.67 Yang Dongfang relative number in May (Table 2). In the central waters of the bay, the horizontal relative loss rate of PHC content in the surface waters is 2.72 Yang Dongfang relative number. The horizontal relative loss rate of PHC content in the surface layer of the northern waters is 6.47 Yang Dongfang relative number. To the northeastern waters of the bay, the horizontal relative loss rate of PHC content in the surface waters is 1.33 Yang Dongfang relative number. Therefore, taking 2106, the central point in the eastern part of Jiaozhou Bay, as the source of marine oil spills, its PHC content decreases to the surroundings, and the horizontal relative loss rate of PHC content is within 1.33-8.67 Yang Dongfang relative number.

Taking the eastern center of Jiaozhou Bay as the source of marine oil spills at $51.00 \mu \mathrm{g} / \mathrm{L}$, a series of concentric circles with different gradients are formed. Then along the gradient, the PHC content decreases to the waters of bay mouth, central waters, northern waters and northeastern waters. The order of PHC content from low to high is: bay mouth waters $<$ northern waters $<$ central waters $<$ northeastern waters. In this way, the horizontal absolute (relative) loss rate of PHC content has a descending order: northeastern waters $<$ central waters $<$ northern waters $<$ waters in the bay mouth. The PHC content shows the value from the same point of the marine oil spill to this water area, and the horizontal absolute (relative) loss rate of PHC content shows the process value from the same point of the marine oil spill to this water area. Therefore, the order of PHC content is opposite to the order of horizontal absolute (relative) loss rate of PHC content. The PHC content shows the value from the same point of the marine oil spill to this water area, and the PHC content horizontal absolute (relative) loss rate shows the process value from the same point of the marine oil spill to this water area.

According to the Yang Dongfang horizontal loss rate model of material content, it is possible to calculate and quantify the migration and changing process of PHC content decreasing along the gradient to the surroundings The PHC content carried by the offshore ocean currents shows the changing law of the PHC content during different migration processes. 1) Along the downstream and upstream directions of ocean currents, the PHC content carried by the ocean currents in the open waters shows different changing results. In the downstream direction of ocean currents, the decline rate of $\mathrm{PHC}$ content reaches the slowest, and the loss of PHC content is the smallest during the migration process. In the countercurrent direction of ocean currents, the PHC content decreases the fastest, and the PHC content loses the most during the migration process. 2) Along the downstream direction of the ocean currents, the length of the migration distance of the PHC content carried by the ocean current in the open waters shows different changing results. In the downstream direction of the ocean current, as the migration distance of the $\mathrm{PHC}$ content continues to increase, the PHC content is continuously decreasing, and the loss of the PHC content is gradually increasing during the migration process. 3) In waters where ocean currents do not pass, the PHC content carried by ocean currents in the open waters shows different results. In waters where ocean currents do not pass, the PHC content decreases slowly, and the $\mathrm{PHC}$ content reaches a relatively high value. The loss of the PHC content during the migration process is relatively small. The loss of PHC content is between the loss of the PHC content carried by the ocean current in the downstream direction and the upstream direction.

\section{References}

1. Dongfang Yang, Fengyou Wang, Sixi Zhu, Xiuqin Yang, Mingzhong Long. Effects of PHC on water quality of Jiaozhou Bay: IAnnual variaiton of PHC content $[\mathrm{J}]$. Meterological and Environmental Research, 2015, 6(11-12): 31-34.

2. Dongfang Yang, Fengyou Wang, Sixi Zhu, Mingzhong Long, Xiuqin Yang. Effects of PHC on water quality of Jiaozhou Bay: IIChanging process of pollution sources $[\mathrm{J}]$. Meterological and Environmental Research, 2016, 7(1): 44-47.

3. Dongfang Yang, Sixi Zhu, Fengyou Wang, Xiuqin Yang, Ming Wang. Effects of PHC on water quality of Jiaozhou Bay: III Land transfer process [J]. Meterological and Environmental Research, 2016, 7(2): 48-51.

4. Dongfang Yang, Fengyou Wang, Sixi Zhu, Ming Wang, Xiuqin Yang. The diffusion of PHC from Jiaozhou Bay to the open waters [J]. Advances in Engineering Research. 2016, 80: 1003-1007.

5. Dongfang Yang, Sixi Zhu, Ming Wang, Xiuqin Yang, Mingzhong Long. Effects of PHC on water quality of Jiaozhou Bay: IV Sedimentation process [J]. Meterological and Environmental Research, 2016, 
7(3): 56-59.

6. Dongfang Yang, Xiancheng Qu, Danfeng Yang, Yu Chen and Yinjiang Zhang. The pollution level of PHC in open waters of Jiaozhou Bay [J]. Advances in Engineering Research. 2016, 88: 1978-1982.

7. Dongfang Yang, Sixi Zhu, Fengyou Wang, Ming Wang, Xiuqin Yang. Effects of PHC on water quality of Jiaozhou Bay: V Water transfer process [J]. Meterological and Environmental Research, 2016, 7(4): 40-43.

8. Dongfang Yang, Fengyou Wang, Sixi Zhu, Mingzhong Long, Xiuqin Yang. Effects of PHC on water quality of Jiaozhou Bay: VI transfer laws [J]. Meterological and Environmental Research, 2016, 7(5): 69-72.

9. Dongfang Yang, Yu Chen, Zhenhui Gao, et al. Silicon Limitation on primary production and its destiny in Jiaozhou Bay, China IV transect offshore the coast with estuaries [J]. Chin. J. Oceanol. Limnol. 2005, 23(1): 72-90.

10. Dongfang Yang, Fan Wang, Zhenhui Gao, et al. Ecological Phenomena of Phytoplankton in Jiaozhou Bay [J]. Marine Science, 2004, 28 (6): 71-74.

11. State Oceanic Administration. The Specification for Marine Monitoring [Z]. Beijing: China Ocean Press, 1991. 